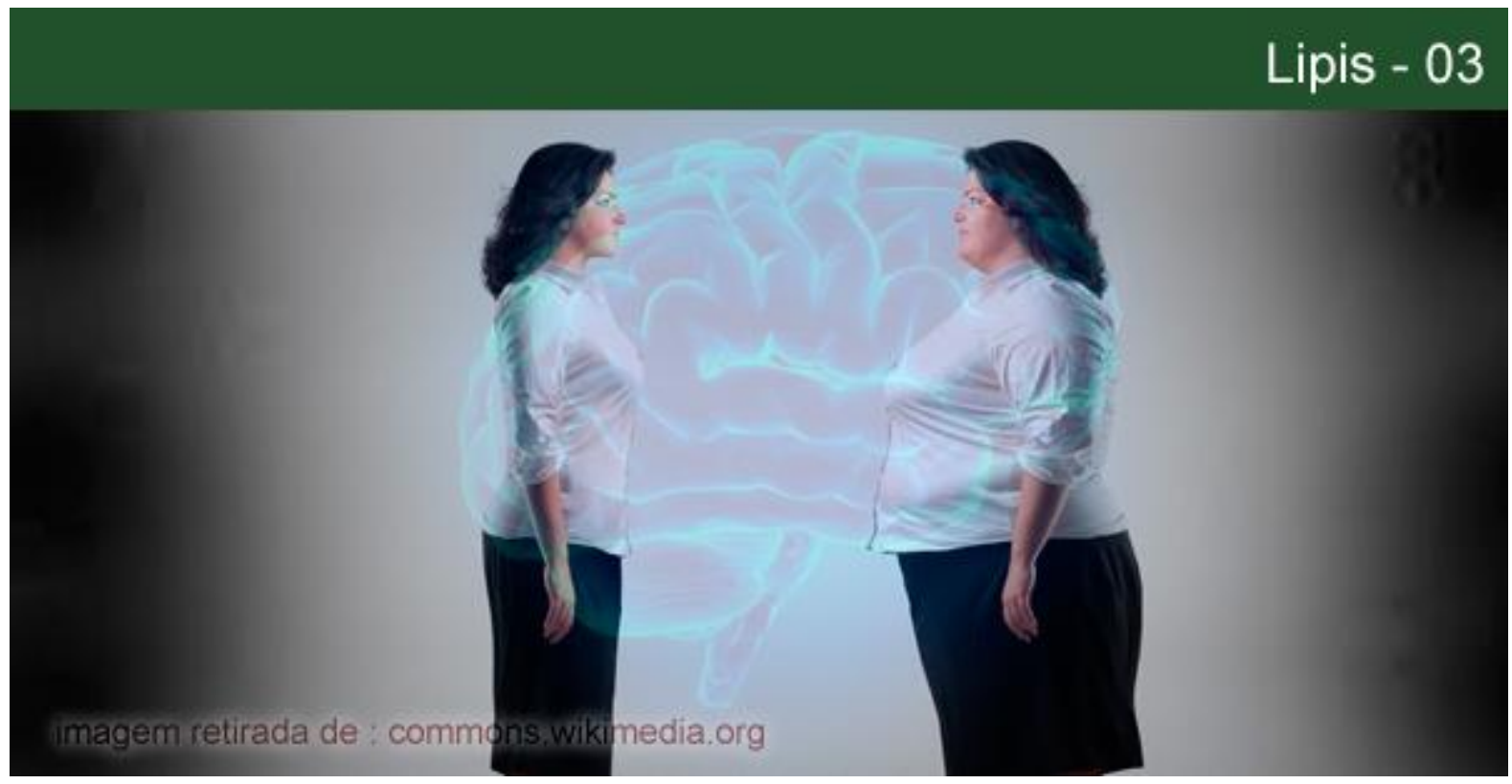

\title{
SOBRE OS DESCAMINHOS QUE LEVAM À CIRURGIA BARIÁTRICA: CORPO, TRAUMA E SOFRIMENTO PSÍQUICO
}

\author{
Natália Salviato Nespoli \\ Mestre pelo Programa de Pós-Graduação em Psicanálise, Saúde e Sociedade da Universidade Veiga de \\ Almeida - UVA (2016). Especialização em Transtornos Alimentares e Obesidade pela Faculdade de Medicina \\ do Hospital das Clínicas da Universidade de São Paulo - FMHC/USP. E-mail: nsnespoli@gmail.com.

\section{Joana de Vilhena Novaes} \\ Professora do Programa de Mestrado Profissional e Doutorado em Psicanálise, Saúde e Sociedade da \\ Universidade Veiga de Almeida. Doutorado em Psicologia Clínica pela PUC-Rio, Pós-Doutorado em \\ Psicologia Social pela UERJ (2008) e em Psicologia Médica pela UERJ (2012). Especialista em Transtornos \\ Alimentares pela Santa Casa de Misericórdia do Rio de Janeiro. Coordenadora do Núcleo de Doenças da \\ Beleza da PUC-Rio. Pesquisadora e Membro do GT de Metodologia do Conselho Consultivo da Fundação Dove \\ para a Auto-estima/UNILEVER. E-mail: joanavnovaes@gmail.com.
}

RESUMO: O objetivo deste artigo é analisar alguns aspectos clínicos e subjetivos relacionados à obesidade, à compulsão alimentar e aos efeitos do processo de emagrecimento. Para tal, daremos especial ênfase aos pacientes submetidos à cirurgia bariátrica. A teoria freudiana, com contribuições posteriores de Lacan, desenvolveu a noção de corpo pulsional. Sob esta ótica, afirmamos a diferença da abordagem corporal pela medicina e pela psicanálise, ressaltando as dimensões culturais e pulsionais do sofrimento psíquico. Em alguns casos, ainda que a medicina tenha alcançado sucesso em sua proposta de emagrecer os corpos, havia algo para além do prazer que retornava sobre os sujeitos. Manifestações de sofrimento psíquico, referentes à obesidade e ao processo de perda de peso na clínica, apontam para a necessidade dos profissionais de saúde atentarem para a melhor forma de acolhimento e manejo do tratamento dos pacientes.

Palavras-chave: Corpo. Obesidade. Cirurgia bariátrica. Pulsão. Trauma. Sofrimento psíquico.

\section{ABOUT SOME DETOURS THAT LEAD TO BARIATRIC SURGERY: BODY, TRAUMA AND PSYCHOLOGICAL DISTRESS}

Abstract: The purpose of this study is to analyze the subjective clinical aspects related to obesity, binge eating, and the effects of the weight loss process, with emphasis on patients subjected to bariatric surgery. Freudian

\section{POLÊM!CA | LABORE (}

Polêmica - Revista Eletrônica da Uerj - Rua São Francisco Xavier, 524, $1^{\circ}$ andar

bloco D, sl.1001 • Tels.: +55 21 2334-4088/4087 • http://www.e-publicacoes.uerj.br/index.php/polemica/index http://www.labore.uerj.br • laboreuerj@yahoo.com.br 
theory, with later contributions by Lacan, developed the notion of the impulse-driven body. Under this point of view, we stress the difference between the medical and the psychoanalytical approaches to the human body, highlighting the cultural and impulse-driven dimensions of the psychic suffering. In some cases, even if the medicine has been successful in its bid to slim the body, there was something beyond the pleasure returned on the subject. Manifestations of psychological distress related to obesity and weight loss in clinical process, point to the need for health professionals to heed the best way to hold and handle, the treatment of patients.

Keywords: Body. Obesity. Bariatric surgery. Drive. Trauma. Distress.

\section{Introdução}

Alguns impasses se impõem ao analista no trabalho com sujeitos que buscam emagrecer, pois muitos enunciam demandas de procedimento médico e não de análise. Embora alguns se tornem sensíveis à escuta que lhes é oferecida e consigam se implicar na própria história, é comum que muitos reproduzam o discurso da necessidade de serem emagrecidos por intervenção médica. Nestas falas, a obesidade é vinculada a uma de suas fontes de maior sofrimento, sendo o ganho de peso associado a fatores que afirmam lhes escapar: hormônios, metabolismo e idade.

Por outro lado, quando estes pacientes iniciam uma narrativa de si, o caráter autobiográfico de sua obesidade passa a tomar evidência. As razões para a gênese do ganho de peso, a necessidade de se livrarem de sua corpulência, os percalços para alcançarem o almejado emagrecimento e, finalmente, a opção pela via cirúrgica e os destinos do corpo após este procedimento estariam agora relacionados à história do paciente e, por conseguinte, a sentidos atribuídos aos acontecimentos experienciados pelo mesmo. A escuta clínica destes casos revelava, muitas vezes, o quanto o corpo constituía lócus de sofrimento.

Um corpo não é composto apenas de órgãos. Para a psicanálise, ele é inseparável da noção de subjetividade. Neste sentido, nem o corpo e nem o sujeito estariam fora do tempo, mas constituiriam um tecido cuja trama é, constantemente, marcada por nuances dos discursos que tecem a malha da cultura. Olhares diversos incidiram sobre o corpo no decorrer da história.

O saber médico detém, na contemporaneidade, hegemonia sobre as práticas corporais. A psicanálise, na contramão do discurso dominante, insiste na existência de um corpo guiado também por uma outra cena, a inconsciente. Considerando que a obesidade, a compulsão alimentar e os tratamentos para emagrecer são noções relacionadas às ciências da saúde, o que estaria ao alcance da prática psicanalítica seria dar atenção à existência de um sujeito ali presente.

\section{POLÊM!CA $\mid$ LABORE}

Polêmica - Revista Eletrônica da Uerj - Rua São Francisco Xavier, 524, $1^{\circ}$ andar

bloco D, sl.1001 • Tels.: +55 21 2334-4088/4087 • http://www.e-publicacoes.uerj.br/index.php/polemica/index

http://www.labore.uerj.br • laboreuerj@yahoo.com.br 
Logo, neste artigo, utilizaremos do escopo da teoria psicanalítica para enfatizar os aspectos subjetivos relacionados aos fenômenos da clínica referentes à temática da obesidade, da compulsão alimentar e aos efeitos do processo de emagrecimento, sobretudo o ensejado pela cirurgia bariátrica. Para isto, serão trabalhadas algumas imagens clínicas, tal como descreveu Fernandes (2001), que se caracterizam por estamparem traços marcantes e insistentes no discurso dos pacientes escutados.

\section{Novas Posições Subjetivas}

Testemunha-se, na contemporaneidade, a ocorrência de uma decadência dos referenciais de avaliação que sustentavam o mundo social. A tradição, a autoridade e a religião já não constituem balizadores dos códigos sociais e as convenções são voláteis. Hoje, proibir é proibido e gozar tornou-se um dever moral (LUSTOZA et al., 2014). Todas estas mutações estabeleceram uma nova organização na produção de sujeitos no que diz respeito às suas relações com os objetos, modos de satisfação, relação com a fala, linguagem, limites e a lei (KOREN, 2013).

Haveria, então, uma inoperância da lei paterna e, adicionalmente, uma relação com os objetos muito específica advinda do capitalismo e sua produção de objetos prontos para gozar. Ao invés de sujeitos desejantes, confrontados com a proibição e com a falta, haveria sujeitos que poderiam, de fato, crer que é possível uma satisfação absoluta. Como se fosse possível de tudo gozar, sem que a castração incidisse (idem).

No campo da clínica, uma série de fenômenos testemunharia o que supomos ser uma consequência desta busca incessante de gozo e da dissolução dos códigos de conduta que governavam a sociedade. Haveria uma disseminação de patologias em que os atos impulsivos se sobreporiam à simbolização (LUSTOZA et al., 2014).

Tais manifestações clínicas consistiriam, por exemplo, em comportamentos antissociais, desregramentos na vida social e amorosa, relações adictas ao objeto de consumo e objetos tóxicos. Relações nunca antes vistas com a linguagem, comunicação e saber, uma crescente intolerância à espera, dentre outros (KOREN, 2013). Destaca-se também, a obesidade, que, embora se saiba não ser novo acontecimento na sociedade, tomou vulto epidêmico na contemporaneidade.

\section{POLÊM!CA $\mid$ LABORE}


Rudge (2006), por sua vez, alerta para os perigos das generalizações acerca da existência de sujeitos coletivos, as quais incorreriam num risco de serem simplificadoras. Ao nos utilizarmos de uma noção diagnóstica para tratar da questão dos sujeitos contemporâneos, eliminaríamos a ideia de singularidade admitindo a existência de um "sujeito médio" (p. 14) que representaria a sociedade. A sociedade é multifacetada e a cultura seria apreendida por cada sujeito a partir de seus próprios aparatos psíquicos.

O trabalho do psicanalista não desconsidera os fatores socioculturais, e nem pode. A noção psicanalítica de Outro marca justamente a importância da dimensão social na estruturação subjetiva. A análise do sujeito, entretanto, supõe, além da investigação cultural e das representações sociais, a valorização do caso a caso. À psicanálise, cabe, portanto, estudar os efeitos da sociedade atual em cada sujeito, investigando suas vicissitudes ao se depararem com as exigências culturais (RUDGE, 2006).

Vilhena e Rosa (2012) afirmam que, ao invés de conceberem a ideia de um sujeito contemporâneo, há novos agenciamentos subjetivos que devem ser considerados na escuta de cada sujeito que sofre. Os obesos, uma vez que a obesidade consiste em tema de interesse desta investigação, não estariam colados em identidades globais.

Não há cultura que seja um todo indistinto. Ela é uma malha reticular, em que comparecem contradições e particularidades. Como afirmaram Vilhena e Rosa (2012, p. 114): “As sociedades não são entidades em si mesmas. Pelo contrário, só existem através dos indivíduos que as atualizam no exercício de suas vidas pessoais [...]”.

Além disso, se o discurso contemporâneo aponta para uma busca desenfreada de gozo, como ressaltado, é importante mencionar o fato de que há sempre uma impossibilidade de atingi-lo por completo. O mal-estar fundamental do ser humano há de comparecer, seja pela via do tédio, advindo dos excessos, ou da decepção - Era só isso? Quero mais, quero outro! (LUSTOZA et al., 2014).

\section{A prática e suas inquietações}

Trabalhar com a obesidade implica que o analista esteja ciente de que deverá lidar, majoritariamente, com os significantes da medicina. Esta forma de tratar o corpo, em que se prioriza sua abordagem fisiológica, é engendrada pelo discurso hegemônico em nossa sociedade. Os pacientes, ao procurarem um serviço de saúde a fim de cuidarem do controle do

\section{POLÊM!CA $\mid$ LABORE}


peso e de suas doenças associadas, portanto, habitualmente, têm uma demanda que é direcionada ao médico. Demanda de serem curados.

Afirmamos, anteriormente, que grande parte dos pacientes, que se apresentam às suas primeiras entrevistas, declaram uma necessidade de perderem peso, atribuindo a ele e ao corpo funcional sua maior insatisfação e embaraço. Para alguns, no entanto, a escuta que lhes era oferecida possibilitava uma torção de suas demandas. Ao pedirem uma análise, estes podiam se atentar para o mais além do que se queixavam: a presença de um mal-estar subjetivo.

É preciso que o psicanalista, neste campo em que os hormônios e o metabolismo são protagonistas, saiba seu lugar. Nas andanças entre profissionais de saúde, congressos sobre cirurgia bariátrica e procedimentos para emagrecer é possível notar uma dissonância, e até uma certa falta de conhecimento, a respeito do que seria a função de um psicólogo ou um psicanalista em uma equipe multiprofissional. Quanto à própria atuação do psicólogo, paira a falta de consenso sobre a melhor forma de abordagem dos pacientes.

E a serviço de que estaria a psicanálise neste âmbito? Certamente que a serviço da escuta de um sujeito que ali está. As entrevistas e o tratamento psicanalítico, desta forma, devem se atentar para a história de cada um, sem intenção antecipada de oferecer um diagnóstico e, tampouco a cura, a qual viria, segundo Freud, como um acréscimo ao processo do tratamento.

Como ganharam peso, relações familiares, representação da comida, relatos minuciosos da alimentação e, portanto, falas a respeito de seus excessos e faltas. $\mathrm{O}$ que comem? Para quê, ou para quem, comem? Tristezas, angústias, alegrias, amores, ódios e seus vínculos com a comida. Corpos compostos de muito mais que órgãos eram os que se apresentavam na clínica.

\section{Engordou por quê? O que dizem os sujeitos do campo acerca do próprio ganho de peso?}

Vimos ocorrer, na contemporaneidade, uma aversão somada à criminalização da gordura (NESPOLI et al., 2015). A lipofobia faz com que muitos pacientes obesos abdiquem de sua rotina de cuidados, pois já pressupõe que serão criticados, ou que terão como primeira recomendação, e condição, para qualquer tratamento, o emagrecimento. Muitos profissionais

\section{POLÊM!CA $\mid$ LABORE}


de saúde lidam de forma moralizadora com a obesidade, como se o sujeito que a eles se apresenta escondesse ou omitisse informações verídicas (NOVAES, 2012).

Assim, ao se apresentarem a um psicólogo que trabalhe junto a uma equipe de saúde, alguns pacientes, esperando que lhes sejam feitas recomendações acerca da melhor gestão do próprio corpo, localizam seu sofrimento no campo anatomofisiólogico. Evidenciando, portanto, o interesse de obterem cura para algumas doenças e até mesmo de prevenção quanto ao futuro, uma vez conscientes sobre o aspecto de letalidade que caracterizam os fatores de comorbidade.

Inicialmente, muitos alocam sua relação com o alimento no campo da necessidade e não fazem associações. Alguns afirmam não haver qualquer mal-estar psíquico referente aos seus corpos. Segundo Rabinovich (2004), haveria alguns sujeitos que chegariam à análise a partir de um lugar que não é sintomático; não dirigem uma questão ao analista. Apresentariam uma forma de ser que não faz pergunta.

É preciso que algo marque uma divisão no sujeito, para que ele possa falar de sua história corporal de um outro lugar e se responsabilize pelas vicissitudes deste corpo próprio. A psicanálise, neste âmbito, apostará na oferta de um espaço, e tempo, para que este movimento de virada possa ocorrer.

Com relação, por exemplo, aos discursos dos pacientes ao tratarem de seu ganho ponderal, enfatizamos aqui, casos em que o ganho de peso foi localizado com o início da vida de trabalho. Quando começaram a ascender economicamente, e ter mais autonomia sobre o dinheiro que recebiam, alguns pacientes relatavam ter passado a comprar mais comida e a fazer refeições qualitativamente melhores. Fato que demonstrou estar em consonância com pesquisa anterior realizada por uma das autoras, Novaes (2010).

Alguns destes sujeitos traziam à clínica relatos de situações alegóricas de suas histórias familiares, com relação à partilha dos alimentos. A pobreza vivida pelos pais de um deles foi tamanha, que precisavam correr atrás de ratos para comer. Assim que seu poder de consumo melhorou, fizeram da comida um bem precioso. Isto pode remeter ao comentário de Freud (1926/1996), ao tratar das formas assumidas pela perturbação da função de nutrição nas afecções neuróticas, quando relaciona a compulsão alimentar ao medo de morrer de fome, salientando, no entanto, o fato de o assunto ter sido, até então, pouco estudado.

\section{POLÊM!CA $\mid$ LABORE}


A obra de Castro (2003) ressalta a curiosidade presente no fato de que, num mundo tão afeito à publicização do conhecimento, haja tão escassa publicação a respeito da fome e de seus efeitos e manifestações. Este silêncio em torno de um tema que, segundo o autor, trata-se de um tabu, escamotearia uma série de preconceitos morais e o entusiasmo econômico de minorias dominantes. Estas, interessadas na distribuição dos alimentos balizada por motivações econômicas e não vinculadas à saúde pública, por exemplo, tenderiam a minorar a importância do fenômeno da fome.

Ainda quanto à questão da gênese do ganho ponderal, é fato comum, escutar de pacientes que anunciavam ter ganho peso após momentos muito difíceis de suas vidas, como quando precisaram cuidar de algum ente querido que passava por doença grave.

Nestes momentos precisaram abdicar dos cuidados consigo para cuidar de quem precisava, ou, ainda, não tinham olhos para si mesmos e precisaram dar mais atenção a quem amavam. Após a melhora ou o falecimento daqueles de quem cuidavam, podiam deslocar o investimento para os cuidados consigo mesmos e relatam haver procurado algum tratamento para emagrecer.

Em alguns casos, a obesidade parece consistir numa solução que operaria a favor de impedir a desorganização psíquica (ANTUNES et al., 2012), ainda que adoeça o sujeito por outras vias. Segundo Coelho dos Santos e Antunes (2006), para alguns sujeitos, o corpo obeso serviria como uma limitação de gozo para o sujeito - o comer em excesso consistiria numa solução para o encontro com o traumático. Ainda que o sujeito, a princípio, pareça absolutamente desregulado, esta seria a forma de encontrar algum contorno.

Tal noção remeteu-me à fala de uma paciente, obesa desde a infância que afirmou, em seu processo de emagrecimento, no pós-operatório da cirurgia bariátrica: "Fiquei com as pernas bambas! Parece que era a gordura que me sustentava!". Sem a obesidade, o sujeito poderia ser "lançado no real sem lei da devastação pulsional" (Ibidem, p. 201). Nisto, vemos a importância de oferecer uma escuta pouco apressada aos pacientes candidatos à cirurgia bariátrica antes que se submetam ao procedimento.

Outros pacientes estabelecem a ocorrência do início de suas obesidades, num período posterior a eventos traumáticos, como uma agressão, seja ela sexual ou não, a perda de esperança de concretizarem um ideal, a perda de alguém que amavam, o término de uma

\section{POLÊM!CA $\mid$ LABORE}


relação. Desta forma, um dos eixos de discussão a respeito da obesidade e sua gênese, girará em torno da noção de trauma.

\section{Trauma e um retorno de um sofrimento}

$\mathrm{Na}$ segunda tópica freudiana, com a descoberta de um além do princípio do prazer, os fundamentos da teoria psicanalítica foram modificados. Colocando em xeque a primazia do prazer no psiquismo e evidenciando a compulsão à repetição da experiência traumática, os sonhos traumáticos, como mencionados no segundo capítulo, dão provas de que nem sempre o aparelho psíquico busca evitar o desprazer. A reformulação da teoria do trauma, antes centrada na questão do trauma sexual infantil, através da investigação das neuroses traumáticas, permitiu a abordagem das patologias em suas apresentações mais recorrentes, atualmente.

Esta "repetição nos caminhos do sofrimento" (RUDGE, 2009, p. 48) foi também observada em outros fenômenos como na reação terapêutica negativa e na compulsão de destino (na qual o sujeito se depara sempre com as mesmas vicissitudes na vida, ainda que estas lhes causem grande sofrimento). Vale ressaltar que as manifestações de repetição são área de intervenção da psicanálise e consistem em fenômeno habitual na clínica.

Rudge (2009) destaca a existência de dois tipos de repetição. Na repetição da criança, em suas brincadeiras e nas histórias que insistem em serem contadas de forma idêntica, por exemplo, ela objetiva elaborar suas experiências. O repetido estaria a favor do princípio do prazer. Em outros casos, a repetição é literal e faz a angústia se atualizar, trazendo à tona o que menos se quer saber.

O homem teria uma disposição ao trauma em decorrência da divisão instaurada por sua entrada na linguagem. Este trauma é estrutural, estruturante. Não se deve, no entanto, desconsiderar o aspecto contingente do trauma e "o efeito devastador com que certas irrupções do Real incidem na vida de alguém” (RUDGE, 2009, p. 64). É este Real que orienta a práxis da psicanálise (LACAN, 1964/2008).

Lacan (1964/2008, p. 59), recorrendo ao vocabulário Aristotélico, faz uso das palavras Tiquê e Autômaton. A primeira traduz como "encontro do Real" e a segunda concebe como retorno dos signos, a insistência da cadeia significante. O Real estaria para além do Autômaton, é o que vige por trás dele.

\section{POLÊM!CA $\mid$ LABORE}


O encontro com o Real se trata do encontro com algo que não tem correspondência no simbólico. Rompe com a situação na qual o Eu se conhecia, colocando-o diante de algo impossível de antecipar. O trauma é considerado um corpo estranho que invadiu o psiquismo (RUDGE, 2009). O “encontro faltoso" (LACAN, 1964/2008, p. 60) se apresenta como um trauma, experiência inassimilável para o sujeito.

A experiência traumática, que deveria ser tamponada pela homeostase subjetivante orientadora do princípio do prazer, insiste em se fazer lembrar - o que Lacan (1964/2008) afirma é que o trauma se faz ressurgir. Seria o ressurgimento do trauma, sua repetição, uma tentativa desta experiência violenta encontrar representação?

Mendlowicz (2006), ressaltando a importância dos eventos atuais na gênese do trauma, destaca que as situações traumáticas estariam relacionadas às perdas: perda de ideais e perda do objeto amoroso, por exemplo. A noção de trauma estaria, segundo a autora, vinculada a uma injúria narcísica grave. Na ocorrência de perdas traumáticas, uma sustentação, que conferia sentido à vida do sujeito é estilhaçada: "O vazio invade a cena psíquica e o sujeito mergulha no desamparo, perdendo a valorização de si próprio. A fragilidade narcísica abre as portas para a entrada triunfal da pulsão de morte [...]" (MENDLOWICZ, 2006, p. 56).

Remetemo-nos então ao caso de uma paciente, quando da sua entrevista prévia à realização da cirurgia bariátrica. Perguntada se era capaz de identificar quando havia começado a ganhar peso, afirma ter sido há sete anos, conta que sua filha a telefonou da casa onde trabalhava, queixando-se de fortes dores de cabeça. Como já considerava a filha queixosa, a paciente, aborrecida, aconselhou que ela pedisse ajuda ao patrão, que era médico. $\mathrm{Na}$ manhã do dia seguinte, recebeu a notícia de que a filha havia morrido - teve um aneurisma. Julgando que as dores de cabeça estavam relacionadas às razões da morte de sua filha, e que não havia conferido a importância que devia à sua fala, caiu em profundo sofrimento.

Começou a ganhar peso, perdeu a vontade de sair de casa e afirmou realizar duas atividades principais na vida: comer e dormir. Deprimida, iniciou uso de inúmeros psicotrópicos, que, segundo o que afirmou, precisavam ficar sob a guarda do marido, que administrava as doses nos horários prescritos, pois ela já havia tentado suicídio ingerindo os medicamentos. Assolada por um sentimento de culpa incurável, mortificava-se.

\section{POLÊM!CA $\mid$ LABORE}


Neste sentindo, seria possível afirmar que o trauma não estaria vinculado apenas a tragédias de grande proporção como as guerras, mas, também, a eventos que carreassem uma invasão de sentimento de desamparo, uma ruptura do Eu (MENDLOWICZ, 2006). Ao nos remetermos ao texto freudiano (1917/1996), observamos que a melancolia ocorreria quando o Eu se identifica ao objeto perdido, a sombra deste recai sobre o Eu. A melancolia implicaria então numa nostalgia, um colamento ao objeto, que se recusa perder.

O sujeito deprimido não conseguiria perder. Não conseguiria substituir um ideal que não se realizou por outro e estaria submisso a um Supereu hostil. A morte se expressaria, assim, de forma recorrente em seu discurso, no que Freud (1917/1996) caracterizou como autodepreciativo. A fala deste sujeito "expressa a derrocada do desejo" (MENDLOWICZ, 2006, p. 58), caracterizada por um lamento que se repete.

Uma outra paciente havia realizado diversos procedimentos para controle do peso, inclusive, a cirurgia bariátrica. Encaminhada para atendimento psicanalítico, pois, ainda assim, havia ganho, novamente, quase todo peso perdido com os procedimentos. O médico, por sua vez, julgava que a falha dos resultados devia-se ao consumo exacerbado de bebidas alcoólicas.

Relatou, então, que antes de ser submetida à cirurgia, gostava de beber, mas o volume de ingestão havia aumentado consideravelmente. Já que não podia comer como antes, algo que lhe trazia enorme prazer, bebia. $\mathrm{O}$ fato de beber em excesso vinha trazendo prejuízos para seu rendimento no trabalho, e além disso, colocava-a em situações arriscadas, pois dirigia e, na maioria das vezes, não lembrava onde estivera e nem como chegava em casa.

Mesmo assim, sofrendo com seus excessos, ela afirmava que não sabia se queria se cuidar. Só procurara o tratamento pois sabia que sua condição preocupava seus familiares. Ela mesma dizia, repetidamente, não ter muitas pretensões e sonhos na vida desde que tinha se atentado para o fato de que seus planos não podiam mais ser realizados: suas relações amorosas estavam fadadas sempre a um fim, não tinha realizado muitas coisas e não conseguia emagrecer, como sonhara. Desta forma, sem considerar que a vida valesse muito à pena, cometia o que nomeava de "pequenos suicídios" - ações que a colocavam em risco.

\section{Inconclusões}

\section{POLÊM!CA $\mid$ LABORE}


O suicídio, na teoria psicanalítica, é tido como uma passagem ao ato bem-sucedida. Lacan (1963/2005), em seu Seminário 10, a respeito do caso Freudiano da jovem homossexual, afirma que a passagem ao ato assume dois significados: tentativa de autopunição e a satisfação de um desejo. De acordo com Roudinesco e Plon (1998), o termo passagem ao ato ressalta a agressividade da conduta mediante a qual o sujeito se precipita numa ação que o ultrapassa.

A manifestação destes acontecimentos na clínica aponta para a necessidade dos profissionais de saúde atentarem para este fenômeno. Nestes casos, ainda que a medicina tenha alcançado sucesso em sua proposta de emagrecer os corpos, havia algo para além do prazer que retornava sobre estes sujeitos. Segundo Freud e Breuer (1893/1996), desde suas primeiras comunicações, a fala, ou a linguagem, consistiria numa substituta da ação, e por isso, mais uma vez sinalizamos a importância da escuta neste processo prévio e posterior à cirurgia.

Numa análise, deve-se apostar na construção de fantasias, como filtro contra o Real traumático. Rudge (2009) afirmou que a construção de narrativas em torno do evento traumático é fundamental, pois pode contribuir com a diminuição da vulnerabilidade diante da falta de sentido a que o trauma expôs o sujeito.

Em alguns dos casos atendidos, um deslocamento subjetivo foi possível, fazendo com que os sujeitos pudessem investir nos cuidados com seus corpos e suas vidas. Em outros, era possível notar uma dificuldade na construção de tais narrativas, o que os fazia permanecer em sofrimento com as perdas de suas histórias, fazendo retornar, sobre o próprio corpo, um sofrimento que não era elaborado.

Nos exemplos clínicos, os pacientes buscaram a cirurgia bariátrica com a intenção de extirparem o que enunciavam ser um grande pesar em suas vidas: a obesidade. $\mathrm{O}$ ganho de peso nestes casos, no entanto, relacionava-se a perdas significativas: da filha ou de um sonho, por exemplo. A cirurgia, ainda que pudesse proporcionar a eles o emagrecimento, daria cabo das suas agruras?

Cabe aos profissionais que se dedicam à escuta de pacientes obesos refletirem acerca do melhor acolhimento, bem como o manejo mais adequado, diante da manifestação de um tipo de mal-estar, tão recorrente na clínica contemporânea.

\section{POLÊM!CA $\mid$ LABORE}




\section{Referências}

ANTUNES, M. C. C.; OLIVEIRA, F. L. G. Tudo que eu gosto é ilegal, imoral ou engorda. Trabalho apresentado em mesa redonda do V Congresso internacional de Psicopatologia Fundamental e XI Congresso Brasileiro de Psicopatologia fundamental, 2012. Disponível em:

<http://www.psicopatologiafundamental.org/uploads/files/v_congresso/mr_4_-

_maria_cristina_da_cunha_antunes_e_flavia_lana_garcia_de_oliveira.pdf>. Acesso em: 27 jun. 2016.

CASTRO, J. A. de. Fome: um tema proibido - últimos escritos de Josué de Castro. CASTRO A. M. (Org.). Rio de Janeiro: Civilização Brasileira, 2003. 239 p.

COELHO DOS SANTOS, T.; ANTUNES, M. C. C. Se todo gordo é feliz, a obesidade é um sintoma ou uma solução? In: BASTOS, A. (Org.). Psicanalisar hoje. Rio de Janeiro: Contra Capa, PPGTO/UFRJ, 2006.

FERNANDES, M. H. As formas corporais do sofrimento: a imagem da hipocondria. Revista Latinoamericana de Psicopatologia Fundamental, IV, 4, 61-80, 2001. Disponível em:

<http://www.psicopatologiafundamental.org/uploads/files/revistas/volume04/n4/as_formas_corporais_do_sofrim ento_a_imagem_da_hipocondria.pdf>. Acesso em: 27 jun. 2016.

FREUD, S. (1893). Sobre o mecanismo psíquico dos fenômenos histéricos: comunicação preliminar (Freud e Breuer). In: Obras psicológicas completas de Sigmund Freud: edição standard brasileira. v. II. Rio de Janeiro: Imago Editora, 1996.

(1917). Luto e Melancolia. In: Obras psicológicas completas de Sigmund Freud: edição standard brasileira. v. XV. Rio de Janeiro: Imago Editora, 1996.

(1926). Inibição, Sintoma e Angústia. In: Obras psicológicas completas de Sigmund Freud: edição standard brasileira. v. XX. Imago Editora, Rio de Janeiro, 1996.

KOREN, D. Destinos do Pai. In: FUKS, B. B.; BASUALDO, C.; BRAUNSTEIN, N. A. (Orgs.). 100 anos de Totem e tabu. Rio de Janeiro: Contra Capa, 2013.

LACAN, J. (1963). Passagem ao ato e acting out. In: . Seminário, livro 10: A angústia. Rio de Janeiro: Jorge Zahar Ed., 2005.

(1964). Tiquê e Autômaton. In: Seminário, livro 11: os quatro conceitos fundamentais da psicanálise. Rio de Janeiro: Jorge Zahar Ed., 2008.

LUSTOZA, R. Z. ; CARDOSO, M. J.E.; CALAZANS, R. "Novos sintomas" e declínio da função paterna: um exame crítico da questão. Ágora (Rio J.), Rio de Janeiro, v. 17, n. 2, p. 201-213, Dec. 2014 . Disponível em: <http://www.scielo.br/scielo.php?script=sci_arttext\&pid=S1516-14982014000200003\&lng=en\&nrm=iso>. Acesso em: 29 mai. 2016.

MENDLOWICZ, E. Trauma e depressão. In: RUDGE, A. M. (Org.). Traumas. São Paulo: Escuta, 2006. p. 51 60 .

NESPOLI, N. S.; NOVAES, J. V.; ROSA, C. N. O corpo na cultura: obesidade como doença, biopolítica e normalização. Desafios - Revista Interdisciplinar da Universidade Federal do Tocantins, v. 1, p. 149-168, 2015. Disponível em:

<http://www.google.com.br/url?q=http://revista.uft.edu.br/index.php/desafios/article/download/1473/8257\&sa= U\&ved=0ahUKEwiFhabZ1fLNAhXCF5AKHU-

JDSUQFggUMAA\&sig2=JrWMvixhsIAB9XtvbHypEg\&usg=AFQjCNG4s5Flb6ej9LpDOWdzk6WD0dDPrQ.> . Acesso em: 13 jul. 2016.

\section{POLÊM!CA $\mid$ LABORE}

Polêmica - Revista Eletrônica da Uerj - Rua São Francisco Xavier, 524, $1^{\circ}$ andar

bloco D, sl.1001 • Tels.: +55 21 2334-4088/4087 • http://www.e-publicacoes.uerj.br/index.php/polemica/index http://www.labore.uerj.br • laboreuerj@yahoo.com.br 
NOVAES, J. V. Com que corpo eu vou? Sociabilidade e usos do corpo nas mulheres das camadas altas e populares. Rio de Janeiro: Ed. PUC/Pallas, 2010.

Você tem fome de quê? Sobre a clínica da obesidade em um hospital público. In: VILHENA, J.;

NOVAES, J. V. (Org.). Corpo para que te quero? Usos, abusos e desusos. Rio de Janeiro: PUC-RIO, Appris, 2012.

RABINOVICH, D. S. Clínica da pulsão - as impulsões. Rio de Janeiro: Companhia de Freud, 2004.

ROUDINESCO, E.; PLON, M. Dicionário de Psicanálise. Trad. Vera Ribeiro. Rio de Janeiro: Jorge Zahar, 1998.

RUDGE, A. M. As teorias do sujeito contemporâneo e os destinos da psicanálise. In: RUDGE, A. M. (Org.). Traumas. São Paulo: Editora Escuta, 2006.

. Trauma. Rio de Janeiro: Jorge Zahar, 2009.

VILHENA, J.; ROSA C. M. Na trama da cultura. A psicanálise para além das quatro paredes. In: RUDGE, A. M; BASSET V. (Org.). Psicanálise e outros saberes. Rio de Janeiro: Cia de Freud, FAPERJ, 2012.

Recebido em: 19/07/2016.

Aceito em: 30/09/2016.

\section{POLÊM!CA $\mid$ LABORE}

Polêmica - Revista Eletrônica da Uerj - Rua São Francisco Xavier, 524, $1^{\circ}$ andar bloco D, sl.1001 • Tels.: +55 21 2334-4088/4087 • http://www.e-publicacoes.uerj.br/index.php/polemica/index http://www.labore.uerj.br • laboreuerj@yahoo.com.br 